\title{
Current perspectives of caffeinated energy drinks on exercise performance and safety assessment
}

This article was published in the following Dove Press journal:

Nutrition and Dietary Supplements

\author{
Richard B Kreider \\ Exercise and Sport Nutrition \\ Lab, Human Clinical Research \\ Facility, Department of Health and \\ Kinesiology, Texas A\&M University, \\ College Station, TX, USA
}

Correspondence: Richard B Kreider Exercise and Sport Nutrition Lab, Human Clinical Research Facility, Department of Health and Kinesiology, Texas A\&M University, College Station, TX 778434243, USA

Tel + I 979458 I498

Email rbkreider@tamu.edu

\begin{abstract}
Energy drinks and energy shots have become very popular among athletes and the general population. They typically contain carbohydrate, caffeine, and other nutrients purported to enhance mental and/or physical performance. Additionally, several caffeine-containing pre-workout supplements have been developed which are commonly consumed as a drink prior to and/or during exercise. While occasional ingestion of these types of products appears to be safe and may offer some ergogenic benefit, individuals who consume these products indiscriminately need to be careful and consider how ingestion of these products may affect the total daily intake of caffeine and other stimulants throughout the day, to minimize any adverse events and/or harmful side effects. This review provides an update as to the current literature on energy drinks and energy shots and provides practical recommendations for their appropriate use among athletes.
\end{abstract}

Keywords: energy drinks, energy shots, pre-workout supplements, exercise performance, cognitive function

\section{Introduction}

Energy drinks (EDs) are among the most common beverages consumed by adolescents and younger adult populations. ${ }^{1,2}$ They typically contain carbohydrate (ie, $10-15 \mathrm{~g} / 100 \mathrm{~mL}$ or $10 \%-15 \%$ solution), electrolytes, and caffeine, along with nutrients purported to improve mental focus, attention, and/or alertness. ${ }^{2}$ Most are considered as beverages and, therefore, have nutrient panels, while others are considered as dietary supplements and, therefore, have supplement fact labels. Most companies also offer a lower calorie version of energy EDs that are flavored with artificial sweeteners. On the other hand, energy shots (ESs) are typically 2-4 oz. servings of concentrated fluid containing nutrients purported to improve mental focus and alertness. Most are classified as dietary supplements. Because EDs and ESs contain carbohydrate, caffeine, and nutrients that may affect cognitive function, they are often consumed by individuals who are tired and need to stay awake for work or school, as well as athletes prior to, during, and/or following exercise as an ergogenic aid or recovery drink. The purpose of this review is to provide an update to a recent position stand from the International Society of Sports Nutrition regarding the scientific literature and make recommendations in regard to the role that ED and/or ES may have on exercise performance, energy expenditure/metabolism, and cognitive function. ${ }^{2}$ Additionally, the safety considerations related to the use of ED and/or ES are discussed. 


\section{Methods}

A comprehensive review of the literature was made by searching the PubMed database of the US National Library of Medicine of the National Institutes of Health. The search strategy involved conducting a keyword search for EDs, ESs, commercial names of EDs and ESs, pre-workout supplements (PWSs), exercise, and performance. Additionally, a search was conducted for the primary nutrients found in EDs and ESs (eg, caffeine, taurine, glucoronolactone, citicoline, green tea, quercetin, and so on). A database of over 1,400 articles was considered for this review.

\section{Nutritional recommendations for athletes}

An ergogenic aid is any training technique, mechanical device, nutritional ingredient or practice, pharmacologic method, or psychological technique that can improve exercise performance capacity and/or enhance training adaptations. ${ }^{3}$ Since many activities require focus and attention to perform well, this also includes improvement of cognitive function. Since EDs and ESs, and PWSs contain nutrients that have been reported to improve physical and cognitive performance, they can serve as ergogenic aids for individuals needing to stay awake and alert, as well as for athletes.

Prior to discussing the ergogenic value of EDs and ESs, it is important to understand how nutrient timing affects exercise. Intense exercise uses carbohydrate as a primary fuel. ${ }^{3,4}$ The higher the intensity, the greater the contribution of carbohydrate to fuel exercise metabolism. ${ }^{5}$ However, the longer you exercise, the greater the contribution of fat as a metabolic fuel. Exercise training spares muscle glycogen utilization at a given exercise intensity, thereby allowing athletes to use fat to a greater degree as a metabolic fuel than carbohydrate at a given exercise intensity. ${ }^{5}$ Ingestion of carbohydrate can serve as an exogenous source of fuel during exercise with an oxidation rate generally between 30 and 60 g/hour, depending on the type of carbohydrate ingested. ${ }^{3,6}$ For this reason, many athletes ingest a blend of lower to moderate glycemic index carbohydrate prior to and during exercise via glucose electrolyte solutions and/or gels. Most athletes engaged in prolonged exercise for $>1$ hour, particularly in hot and humid environments, consume glucose electrolyte solutions (ie, sports drinks) in order to maintain carbohydrate availability and prevent dehydration.,

In addition to carbohydrate, there are several nutrients that have been reported to affect exercise performance capacity and/or spare muscle glycogen utilization during exercise, thereby allowing athletes to exercise for a longer period of time before fatigue. ${ }^{3}$ For example, caffeine has been reported to increase the release of free fatty acids during exercise and promote fat oxidation, thereby also sparing muscle glycogen utilization during exercise. ${ }^{7}$ Numerous studies have reported that caffeine ingestion prior to and/or during prolonged exercise enhances endurance exercise performance capacity., ${ }^{2,-9}$ Additionally, acute ingestion of caffeine has been reported to enhance high-intensity intermittent exercise capacity. ${ }^{10-14}$ Therefore, there is rationale for athletes to use EDs and/or ESs prior to and/or during exercise simply as a convenient way to ingest caffeine.

EDs and ESs also typically contain nutrients purported to promote cognition and/or mental focus (eg, taurine, Ginkgo biloba, L-tyrosine, citicoline, 5-hydroxy-L-tryptophan, St John's Wort, and so on), stimulants (eg, caffeine, guarana, green tea, synephrine, yerba mate, yohimbine, tyramine, vinpocetine, and so on), and/or various purported ergogenic nutrients (eg, Panax ginseng, L-carnitine, D-ribose, $\beta$-alanine, inositol, citrulline, quercetin, and so on). ${ }^{2}$ While not all of these nutrients have been reported to affect exercise and/or cognitive function ${ }^{3,15}$ and the amounts found in EDs and ESs are often lower than the effective doses reported in the literature, ${ }^{2}$ the addition of these nutrients to EDs and ESs may provide some benefit for improving the cognitive function, particularly toward the end of an exercise training bout or competition. They may also provide benefit for individuals who are tired and/or need to maintain focus for work and/or study.

In terms of timing of nutrient intake around an exercise bout, it is recommended that athletes ingest a pre-exercise snack 30-60 minutes prior to exercise, containing 40-50 g of carbohydrate and 5-10 g of protein. ${ }^{3,16,17}$ Additionally, that athletes ingest caffeine prior to prolonged endurance exercise performance. ${ }^{3,7}$ Therefore, as long as consumption of the ED prior to exercise does not promote hypoglycemia, some EDs may serve as an effective pre-workout snack, particularly if they include carbohydrate, amino acids, and caffeine. During exercise lasting $>1$ hour, particularly in hot and humid environments, it is recommended that athletes consume about $0.75 \mathrm{~L} /$ hour of water depending on the sweat rate, or a glucose electrolyte solution (6\%-8\% solution). ${ }^{3,18,19}$ Consequently, some athletes use diluted EDs during prolonged exercise as a means of providing carbohydrate, caffeine, and electrolytes. Within 30-60 minutes after exercise, it is recommended that athletes ingest $0.5-1.0 \mathrm{~g} / \mathrm{kg}$ body mass of carbohydrate to promote glycogen replenishment, as well as $0.25-0.5 \mathrm{~g} / \mathrm{kg}$ body mass of protein. ${ }^{3,16-19}$ Thus, some athletes consume EDs after exercise along with some protein as a way to promote carbohydrate replenishment and recovery. 


\section{Effects on exercise performance}

Energy drinks

Several studies have evaluated the effects of ingesting EDs, ESs, and/or PWSs on exercise performance. Much of the interest in use of EDs as an ergogenic aid was generated after Red Bull ${ }^{\circledR}$ (RB) was introduced into the market place. One serving of RB (about $250 \mathrm{~mL}$ ) contains about $28 \mathrm{~g}$ of carbohydrate ( $11.3 \%$ solution) mostly from sucrose and glucose, taurine $(1,000 \mathrm{mg})$, glucuronolactone $(600 \mathrm{mg})$, sodium (100 mg), caffeine (80 mg), B vitamins (niacin [100\%], vitamin B6 [250\%], vitamin B12 [80\%], and pantothenic acid [50\%]) from ingredients that include carbonated water, citric acid, sodium bicarbonate, caffeine, niacinamide, calcium pantothenate, pyridoxine $\mathrm{HCl}$, and vitamin $\mathrm{B} 12$. Thus, $\mathrm{RB}$ can serve as an effective source of carbohydrate and caffeine prior to exercise with some potential additive benefits from taurine and/or glucuronolactone on cognitive function.

There have been several studies that have evaluated the ergogenic value of RB on exercise performance. For example, Alford et $\mathrm{al}^{20}$ investigated the effects consuming $\mathrm{RB}$, a carbonated water beverage, or no beverage at all 30 minutes prior to performing an endurance exercise bout. Results revealed that endurance performance was increased by $8 \%$ and $14 \%$ following RB ingestion compared to the carbonated water and no beverage treatment, respectively. Similarly, Ivy et $a l^{8}$ evaluated the effects of trained cyclists consuming RB providing $\sim 2.3 \mathrm{mg} / \mathrm{kg}$ body mass of caffeine or a flavored placebo 40 minutes prior to performing a 1-hour time trial at $70 \%$ of maximal power output. Results revealed that participants ingesting RB completed the time trial $\sim 4.7 \%$ faster than placebo treatment. ${ }^{8}$ Moreover, Rahnama et $\mathrm{a}^{21}$ investigated the effects of ingesting of RB or Hype ${ }^{\circledR}$ (containing $24.8 \mathrm{~g}$ carbohydrate, $75 \mathrm{mg}$ caffeine, $1 \mathrm{~g}$ taurine, and $600 \mathrm{mg}$ glucuronolactone) 40 minutes prior to performing a maximal exercise capacity test compared to a placebo containing water and citrus substances. Results revealed that ED consumption increased maximal aerobic capacity and time to exhaustion, with no differences observed in heart rate or lactate responses. These findings suggest that ingestion of RB prior to exercise can enhance endurance exercise performance and/or maximal exercise capacity.

Some studies also indicate ingestion of EDs before resistance exercise can affect exercise capacity. For example, Forbes et $\mathrm{al}^{22}$ gave 15 physically active college-aged students RB (standardized with $2 \mathrm{mg} / \mathrm{kg}$ body mass of caffeine) or a placebo 60 minutes prior to exercise. The researchers reported that RB significantly increased total bench press repetitions over three sets by $6 \%$, with no effect on cycling anaerobic sprint peak or average power. Del Coso et $\mathrm{al}^{23}$ evaluated the effects of RB ingestion containing 1 or $3 \mathrm{mg} /$ $\mathrm{kg}$ body mass of caffeine or a placebo 60 minutes prior to performing bench press and squat resistance exercise. Results revealed that ingestion of the ED with $3 \mathrm{mg} / \mathrm{kg}$ body mass of caffeine increased maximal power output by $7 \%$ in both half squat and bench press, as compared to the ingestion of a placebo. However, the lower caffeine dose had no effect on performance. Gonzalez et $\mathrm{al}^{24}$ reported that ingestion of $\mathrm{RB}$ 10 minutes prior to exercise increased the number of repetitions performed during four sets of the squat or bench press exercise using $80 \%$ of the subject's one repetition maximum by $11.9 \%$. In addition, the average power output for the workout was significantly higher for subjects consuming RB.

However, not all studies found significant effects. For example, Candow et al ${ }^{25}$ reported ingestion of $2 \mathrm{mg} / \mathrm{kg}$ body mass of sugar-free RB 1 hour prior to exercise had no effects on run time to exhaustion performed at $80 \%$ of peak oxygen uptake. Likewise, Astorino et $\mathrm{a}^{26}$ reported that RB ingestion 60 minutes prior to repeated agility tests in female soccer players had no significant effects on performance. Nevertheless, majority of the studies indicate that RB ingestion prior to exercise can influence exercise performance capacity.

\section{Energy shots}

A couple of studies have evaluated the effects of ES ingestion on exercise performance. For example, Schubert et $\mathrm{al}^{27}$ evaluated the effects of consuming an ES on $5 \mathrm{~km}$ time trial performance in trained runners. Participants ingested a placebo $\left(2 \mathrm{oz}\right.$. of Dragonfruit Vitamin Water ${ }^{\mathrm{TM}}$ with no caffeine), Guayaki Yerba Mate ${ }^{\mathrm{TM}}$ Organic ES containing $80 \mathrm{mg}$ of caffeine, or RB Energy Shot ${ }^{\mathrm{TM}}$ containing $80 \mathrm{mg}$ caffeine in a randomized, counterbalanced, and crossover manner prior to performing a $5 \mathrm{~km}$ time trial on a treadmill. The researchers found that time trial performance was not affected by ES ingestion. Conversely, Seifert and Connor ${ }^{28}$ evaluated the effects of consuming Body Glove Surge ${ }^{\circledR}$ (18 g carbohydrates, $3 \mathrm{~g}$ protein, and $150 \mathrm{mg}$ caffeine per serving), 5-Hour Energy $^{\circledR}$ ( $\sim 205 \mathrm{mg}$ caffeine, $\sim 480 \mathrm{mg}$ taurine, $30 \mathrm{mg}$ niacin), or a non-caloric placebo on time trial performance following cycling for 120 minutes at $70 \%$ of peak oxygen uptake with intermittent 2-minute intervals at $90 \%$ of peak oxygen uptake. Participants ingested a half dose of the ESs at 30, 60, and 90 minutes of exercise, with $75 \mathrm{~mL}$ of water. Participants then performed a 6-minute time trial. Results revealed that ingestion of the ES containing carbohydrate, protein, and caffeine significantly improved cycling power output and auditory response time following 2 hours of moderate and 
high-intensity interval cycling compared to RB and placebo ingestion. Marczinski et $\mathrm{al}^{29}$ reported that ingestion of an ES (5-Hour Energy) did not affect reaction times or inhibition failures while performing behavioral control tasks (the cued go/no-go task) in comparison to consuming a cranberry juice placebo or no drink. Similarly, Monaghan et $\mathrm{al}^{30}$ reported that ES ingestion (5-Hour Energy Extra Strength Berry Flavor) 30 minutes prior to law enforcement officers participating in target shooting impaired pistol steadiness in comparison to ingesting a flavored water placebo, suggesting an ergolytic effect on fine motor skill. Although more research is needed, these findings suggest that ES ingestion has less consistent effects on exercise and/or motor skill performance than ED consumption.

\section{PWSs}

PWSs have also become a popular pre-workout beverage. They are typically available in a powder form that is added to water and consumed as an energy drink prior to exercise. Some companies also offer a ready-to-drink (RTD) version of their PWSs. These products generally have a small amount of carbohydrate, caffeine, and nutrients purported to improve acute exercise capacity. Some also include nutrients that can help training adaptations. For example, Walsh et $\mathrm{al}^{31}$ evaluated the effects of ingesting a sugar-free ED containing $\sim 2 \mathrm{~g}$ of caffeine, taurine, and glucuronolactone with amino acids (L-leucine, L-isoleucine, L-valine, L-arginine, and L-glutamine) 10 minutes prior to performing a run to exhaustion test at $70 \%$ of peak oxygen uptake. ${ }^{31}$ The researchers reported that participants ingesting the PWS were able to run $12.5 \%$ longer than during placebo treatment (flavored and colored water). ${ }^{31}$ Hoffman et $\mathrm{al}^{32}$ evaluated the effects of ingesting a PWS containing branched chain amino acids (BCAAs), creatine, taurine, caffeine, and glucuronolactone on resistance training performance (six sets of 10 repetitions at $75 \%$ of one repetition maximum). Results revealed that performance was enhanced during set 5 of the exercise bout, and the total number of repetitions and the lifting volume only tended to be greater. However, growth hormone and insulin levels were higher following PWS ingestion compared to a maltodextrin placebo. Smith et $\mathrm{al}^{33}$ reported that ingestion of a PWS drink containing $18 \mathrm{~g}$ of whey protein, Cordyceps sinensis, creatine, citrulline, ginseng, and caffeine 30 minutes prior to exercise during 3 weeks of high-intensity interval training significantly increased peak oxygen uptake, critical velocity, fat-free mass, and training volume in comparison to an isocaloric flavored placebo containing maltodextrin.
Furthermore, Jagim et $\mathrm{l}^{34}$ evaluated the effects of ingesting a multi-ingredient PWS (4 g carbohydrate, 130 $\mathrm{mg}$ sodium, $2 \mathrm{~g}$ creatine hydrochloride, $2 \mathrm{~g}$ beta-alanine, $1.5 \mathrm{~g}$ betaine, $1 \mathrm{~g}$ taurine, $600 \mathrm{mg} N$-acetyl L-cysteine, 300 mg alpha-glyceryl phosphoryl choline, $6 \mathrm{~g}$ citrulline malate, $500 \mathrm{mg}$ beta vulgaris [beet root extract], $3 \mathrm{~g}$ L-leucine, $1.5 \mathrm{~g}$ L-isoleucine, $1.5 \mathrm{~g}$ valine, $1.5 \mathrm{~g}$ L-tyrosine, $300 \mathrm{mg}$ caffeine anhydrous, $50 \mathrm{mcg}$ huperzine $\mathrm{A}$, and $5 \mathrm{mg}$ Piper nigrum fruit extract) 30 minutes prior to performing a counter movement vertical jump test, five sets of five repetitions at $85 \%$ of 5 repetition maximum on the back squat and bench press, followed by a single set to failure, and an anaerobic capacity sprint test. Results revealed that the number of repetitions during the bench press, as well as anaerobic sprint capacity, were increased to a greater degree following PWS ingestion in comparison to a flavor and color match water placebo. Similarly, Martinez et al ${ }^{35}$ reported that ingestion of a PWS containing carbohydrate, $\beta$-alanine, creatine nitrate, L-tyrosine, ribose, amino acids, and caffeine and other nutrients significantly improved anaerobic peak and mean power in comparison to ingesting a color- and flavor-matched maltodextrin placebo. Jung et $\mathrm{al}^{36}$ evaluated the effects of ingesting a PWS containing beta-alanine $(3 \mathrm{~g})$, creatine nitrate ( 2 g), arginine alpha-ketoglutarate ( $2 \mathrm{~g}), \mathrm{N}$-acetyl-L-tyrosine $(300 \mathrm{mg})$, and caffeine $(284 \mathrm{mg}$ ) with and without $20 \mathrm{mg}$ of synephrine on resting energy expenditure and acute exercise performance. The researchers reported that PWS ingestion prior to exercise increased resting energy expenditure but had limited effects on muscular endurance and anaerobic sprint capacity in comparison to ingesting a color- and flavormatched maltodextrin placebo. Further, adding synephrine did not provide additive benefits.

Collins et $\mathrm{al}^{37}$ investigated the effects of ingesting a placebo beverage or an RTD PWS containing caffeine (200 mg), beta-alanine $(2.1 \mathrm{~g})$, and arginine nitrate $(1.3 \mathrm{~g})$ for 7 days on exercise performance. The researchers found that acute PWS ingestion-maintained recovery leg press strength to a greater degree, increased leg press repetitions to failure, and increased bench press and total lifting volume in comparison to a flavor- and color-matched dextrose placebo. However, $4 \mathrm{~km}$ cycling time trial performance was not affected by acute PWS ingestion. Finally, Cameron et $\mathrm{al}^{38}$ evaluated the effects of ingesting multi-ingredient PWS containing caffeine, $\beta$-alanine, beet root extract along with some nutrients purported to enhance cognitive function on the resting metabolism and exercise performance in recreationally active females. Results revealed that PWS ingestion increased the 
resting metabolism and improved upper body muscular endurance and anaerobic capacity in comparison to a flavorand color-matched placebo. Collectively, these findings and others provide evidence that ingesting PWSs prior to exercise can affect acute exercise capacity.

\section{Effects on cognitive performance Energy drinks}

A number of studies have also assessed the effects of consuming EDs on cognitive performance. For example, Seidl et $\mathrm{al}^{39}$ evaluated the effects of ingesting $\mathrm{RB}$ on mood and motor function in fatigued participants. The researchers found that reaction time was significantly longer in the placebo group (wheat bran with water) but remained unchanged in the ED group. Additionally, vitality scores, feelings of well-being, and social extroversions were significantly decreased in the placebo group, while they remaining unchanged in the ED group. ${ }^{39}$ In a similar study, Howard and Marczinski ${ }^{40}$ reported that consuming $1.8,3.6$, or $5.4 \mathrm{~mL} / \mathrm{kg}$ of $\mathrm{RB}$ decreased reaction times on the behavioral control task, increased subjective ratings of stimulation, and decreased ratings of mental fatigue, compared to a placebo beverage and nondrink treatment. The greatest improvements were observed with the lower dose and improvements diminished as the dose increased.

Mets et $\mathrm{al}^{41}$ evaluated the effects of consuming RB or a placebo drink (RB drink containing no taurine, caffeine, or glucuronolactone) after 2 hours of simulated driving before driving for an additional 2 or 4 hours of uninterrupted driving. Results revealed that RB consumption significantly improved driving relative to placebo, including improving SD of lateral position, fourth hour of driving, the SD of speed, subjective driving quality, and mental effort to perform the test during the third hour of driving. The researchers also found that RB ingestion decreased subjective sleepiness during the third and fourth hour of driving and uninterrupted driving. Moreover, Wesnes et $\mathrm{al}^{42}$ evaluated the effects of sugar and non-sugar containing RB on cognitive function and mood compared to a carbonated water and RB-flavored placebo in healthy young volunteers. Results revealed that both versions of RB significantly improved memory and speed of correct responses on memory and recognition tests. Rao et $\mathrm{al}^{43}$ reported that ingesting an ED containing $40 \mathrm{mg}$ of caffeine and $60 \mathrm{~g}$ of glucose enhanced the measures of electroencephalogram brain activity in comparison to a color- and taste-matched placebo. The authors concluded that improved brain activity could translate to improvements in reaction time.
Scholey and Kennedy ${ }^{44}$ investigated the effects of ingesting 1) a color- and flavor-matched ED placebo beverage; 2) ED containing caffeine ( $75 \mathrm{mg}) ; 3$ ) ED containing glucose (37.5 g); 4) ED containing ginseng (12.5 mg) and G. biloba $(2.0 \mathrm{mg})$; or 5) ED containing all of these nutrients 30 minutes prior to performing cognitive performance and mood assessments. The researchers reported that secondary memory and speed of attention were significantly improved with ED ingestion compared to a placebo beverage. ${ }^{44}$ Smit et $\mathrm{al}^{45}$ conducted three studies to assess the effects of EDs containing carbohydrate, caffeine, and taurine with and without carbonation on motor task performance, mood, and side effects. Results revealed that caffeine was most likely the primary ingredient that improved mood and performance during fatiguing and cognitively demanding tasks, with carbohydrates playing a minor role. Collectively, these reports provide some support that ingestion of EDs prior to exercise can affect cognitive performance.

\section{Energy shots}

Only one published paper was found that reported the effects of ingesting an ES on cognitive performance. In this study, Marczinski et $\mathrm{al}^{29}$ assessed the effects of acute ingestion of a popular ES (5-Hour Energy) on subjective and objective psychological measures for 6 hours following consumption. Participants ingested the ES, a cranberry juice placebo, or no drink while completing Profile of Mood States ratings hourly for 6 hours. Results revealed that ES ingestion did not significantly affect subjective ratings of vigor and fatigue, although vigor values were maintained to a greater degree and fatigue values were consistently lower with ES ingestion.

\section{Pre-workout supplements}

Hoffman et $\mathrm{al}^{46}$ found that when male strength/power athletes consumed $120 \mathrm{~mL}$ of a commercially available ED (Redline Extreme ${ }^{\circledR}$ containing caffeine anhydrous, beta-alanine, vitamin $\mathrm{C}$, and the following herbal and botanical compounds: evodiamine, $N$-acetyl-L-tyrosine, hordenine, 5-hydroxytryptophan, potassium citrate, $N$-methyl tyramine, sulbutiamine, vinpocetine, yohimbine $\mathrm{HCl}$, and St John's wort extract) or a color- and flavor-matched placebo, reaction time and subjective feelings of energy and focus were significantly improved in those consuming the ED. Walsh et $\mathrm{al}^{31}$ reported that PWS consumption 10 minutes prior to exercise promoted perceptions of greater focus, energy, and less fatigue prior to exercise and improved the ratings of focus and energy 10 minutes into exercise. However, perceptions of energy, fatigue, and focus were not affected following exercise. ${ }^{31}$ 
Jagim et $\mathrm{al}^{34}$ found that PWS ingestion 30 minutes prior to resistance exercise improved subjective ratings of fatigue and alertness. Likewise, Jung et $\mathrm{al}^{36}$ reported that ingestion of a PWS containing beta-alanine, creatine nitrate, arginine alpha-ketoglutarate, $N$-acetyl-L-tyrosine, and caffeine prior to exercise improved the perceptions about readiness to perform and cognitive function. Finally, Cameron et $\mathrm{al}^{38}$ reported that ingestion of a multi-ingredient PWS improved the feelings of focus following high-intensity exercise in recreationally active females. Collectively, these findings suggest that consumption of PWSs can affect cognitive performance and/or psychological perceptions related to exercise.

\section{Frequent use of EDs, shots, and PWSs}

A number of studies have evaluated the effects of daily ingestion of one to two servings a day of RTDs or PWSs for up to 10 weeks on training adaptations and markers of safety in healthy individuals. These studies provide insight as to the impact of frequent ED and PWS on performance and markers of health. For example, Smith et $\mathrm{l}^{33}$ evaluated the effects of ingesting a PWS containing caffeine $(100 \mathrm{mg})$, creatine (1.5 g), BCAA (1 g), whey protein (9 g), C. sinensis (2.5 g), citrulline $(0.75 \mathrm{~g})$, and Rhodiola taken 30 minutes prior to high-intensity interval training for 3 weeks. The researchers found that PWS consumption significantly increased peak oxygen uptake, critical velocity, and gains in fat-free mass. Ormsbee et $\mathrm{al}^{47}$ evaluated the effects of consuming one serving of whey protein, casein protein, BCAA, creatine, beta alanine, and caffeine (NO-Shotgun ${ }^{\circledR}$ ) before each resistance training workout and one serving of whey protein, casein protein, BCAA, creatine, and beta alanine (NO-Synthesize ${ }^{\circledR}$ ) immediately after each workout and on non-resistance training days for 6 weeks on training adaptations. The researchers reported that pre- and post-exercise supplementation of these supplements promoted greater gains in fat-free mass and improvements in anaerobic capacity. Kedia et $\mathrm{al}^{48}$ evaluated the effects of ingesting a PWS containing creatine, betaine, and Dendrobium extract on training adaptations during 6 weeks of resistance training. Participants taking the PWS reported significantly greater subjective ratings of energy and concentration and less fatigue. However, PWS ingestion did not affect changes in body compensation or performance.

Collins et $\mathrm{al}^{37}$ reported that 5 days of ingestion of an RTD PWS containing caffeine $(200 \mathrm{mg})$, beta-alanine $(2.1$ $\mathrm{g})$, and arginine nitrate (1.3 g) prior to exercise maintained recovery leg press strength, endurance, and lifting volume to a greater degree than ingesting a placebo. However, $4 \mathrm{~km}$ cycling time trial performance was not affected by short-term
PWS ingestion. Jung et $\mathrm{al}^{11}$ evaluated the effects of daily consumption of two doses of a popular PWS with and without $p$-synephrine for 8 weeks on training adaptations in resistance-trained athletes. Results revealed evidence that 4 weeks of PWS and PWS with $p$-synephrine improved some indices of cognitive function and exercise performance during resistance training in apparently healthy males. However, these effects were similar to placebo ingestion after 8 weeks of supplementation, suggesting that the ergogenic benefits may fade over time.

Arent et $\mathrm{al}^{49}$ evaluated the effects of consuming a multiingredient PWS containing raspberry ketone, capsaicin, caffeine, garlic, and Citrus aurantium for 8 weeks on weight loss in overweight adults participating in an exercise and diet program. Results revealed that men taking the PWS experienced greater gains in fat-free mass, while women experienced greater loss in hip circumference. Additionally, PWS ingestion promoted greater reduction in leptin and increases in adiponectin, suggesting an impact on appetite hormones. No adverse effects were reported. Finally, Lockwood et al ${ }^{50}$ evaluated the effects of consuming an ED containing $1.8 \mathrm{~g}$ of a proprietary blend containing taurine, caffeine, green tea extract, glucuronolactone, and ginger extract with vitamins and minerals daily for 10 weeks with and without exercise on body composition, exercise capacity, and markers of health. The researchers reported that daily pre-workout ED consumption without exercise had no effects on body composition, cardiorespiratory fitness, or strength in sedentary males. However, when combined with exercise, pre-exercise and daily ED consumption improved some physiological adaptations to endurance and resistance training. Collectively, these findings suggest that daily ingestion of ED and/or PWSs may appear to enhance training adaptations.

\section{Safety considerations}

The clear majority of studies that have evaluated the acute ingestion of ED, ES, or PWS on exercise and/or cognitive performance have shown they are well tolerated in healthy individuals. Additionally, the studies described above reported that daily and pre-exercise consumption of EDs or PWSs for up to 10 weeks during training was well tolerated and not associated with any serious adverse effects. ${ }^{11,33,37,47-56}$ Nevertheless, a few studies have reported that acute ingestion of ES, ED, and/or PWS caused a short-term increase in resting systolic and/or diastolic blood pressure generally in the $2-5 \mathrm{mmHg}$ range. ${ }^{29,57,58}$ However, the reported changes were typically less than observed from standing up or light walking, and most studies have found that acute $36,50,58,59$ 
and longer-term ingestion of ED, ES, or PWS ${ }^{11,47,49-56}$ had no effects on resting or exercise blood pressure. Moreover, Collins et $\mathrm{al}^{37}$ reported that PWS ingestion had no effects on hemodynamic responses to a postural challenge and Molnar and Somberg ${ }^{60}$ reported improved endothelial function after ingestion of some EDs, which could provide health benefit. ${ }^{60}$ Nevertheless, it would be prudent for individuals with hypertension to exercise caution when consuming ED, ES, and/or PWS, as they may cause a small transient increase in systolic blood pressure.

Concerns have been raised about the indiscriminant use of EDs and ESs. ${ }^{61-64}$ This includes concern about the use of EDs to counteract the depressive effects of alcohol, which, may lead to excessive alcohol intake and/or intoxication. ${ }^{59,65-69}$ For example, several studies suggest that individuals who mix alcohol with EDs are more likely to consume more alcohol and/or engage in risky behaviors. ${ }^{70-81}$ While discussing the effects of concomitant use of EDs with alcohol goes beyond the scope of this paper, it is clear that consumption of EDs with alcohol may increase the likelihood of intoxication and risky behavior, and should therefore be discouraged. For more information on this topic, the reader is referred to a comment published by the American Medical Association related to the safety concerns of mixing ED with alcohol. ${ }^{82}$

Concerns have also been raised that the indiscriminate use of EDs and/or ESs may lead to excessive caffeine intake and negative health outcomes. ${ }^{83-88}$ It should be noted that the amount of caffeine found in most standard size EDs and ESs (ie, about $80-200 \mathrm{mg}$ ) is less than that found in a premium cup of coffee depending on the size (eg, 180-475 mg) and some soft drinks; yet, these types of concerns have generally not been raised about the use of these products. Nevertheless, if individuals do not carefully monitor their caffeine intake, it is possible to unknowingly ingest high levels of caffeine. For example, if an individual had a premium cup of coffee, several high caffeine-containing soft drinks, and several EDs, ESs, and/or PWSs per day, he/she could have easily consumed 1,000-2,000 mg of caffeine or more per day, particularly if the amount of caffeine contained in these products is not clearly labeled.

According to the Council for Responsible Nutrition, ${ }^{89}$ by law, manufacturers are permitted to label and market liquids or as a dietary supplement if it is intended to supplement the diet. ED marketed as beverages will have a "Nutrition Facts" panel, while those marketed as a dietary supplement will have a Supplement Facts panel. The US Food and Drug Administration issued guidance to industry suggesting that products should clearly label serving sizes and ingredient content (including caffeine), and that products packaged in containers larger than $8 \mathrm{oz}$. should be labeled as a beverage. The Code of Federal Regulations in the USA limits the amount of caffeine that can be added to soft drinks to $0.02 \%$ by volume or about $70 \mathrm{mg}$ caffeine per $12 \mathrm{oz}$., as this is considered by the US Food and Drug Administration as generally recognized as safe. ${ }^{89}$ The Nutrition Facts Panel on food labels is not required to always list caffeine since it is not a nutrient. ${ }^{2}$ However, if caffeine is added to a food, it must then be listed. ${ }^{89}$ For this reason, it is possible for individuals to unknowingly consume more caffeine in the diet than they realize, particularly if it comes from food or beverages that do not describe the total caffeine intake from all sources. ${ }^{83,84,86,87}$

The potential side effects of caffeine include insomnia, nervousness, restlessness, gastric irritation, nausea, vomiting, tachycardia, tremors, and anxiety, with doses as low as 250-300 mg. ${ }^{82,86,90,91}$ While caffeine is naturally found in high amounts in the food supply and is considered generally recognized as safe as noted above when consumed in moderation, ${ }^{92}$ any substance could be toxic at high-enough doses or pose a health risk to some medical populations and/or in individuals who are genetically more sensitive to caffeine. Nawrot et $\mathrm{al}^{93}$ reported ingestion of up to $400 \mathrm{mg}$ of caffeine $(6 \mathrm{mg} / \mathrm{kg})$ was not associated with any adverse effects in adults, and Higdon and Frei ${ }^{94}$ suggested that children can typically tolerate doses $<3 \mathrm{mg} / \mathrm{kg}$ per dose without untoward side effects. However, one must also consider whether there are any other stimulants in the ED, ES, or PWS, as there may be additive and/or synergistic effects. ${ }^{2}$

Thus, it is advisable to consider consuming only the EDs, ESs, and PWSs that have been assessed for acute and longer-term safety as described in the studies above. Finally, since some EDs contain relatively large amounts of sugar, it is advisable that individuals with diabetes mellitus or pre-diabetes mellitus should avoid excessive consumption of high glycemic EDs or PWSs. Therefore, it would be prudent for individuals with uncontrolled hypertension, arrhythmias, diabetes mellitus, peripheral artery disease, and/or cardiovascular disease to avoid use of EDs, ESs, and/ or PWSs with known cardiostimulant effects. ${ }^{2}$ While the available evidence to date suggests that use of EDs, ESs, and/or PWSs is generally well tolerated and safe in healthy populations when used as intended and is similar to ingesting other foods and beverages containing caffeine, care should be taken to consider all sources of caffeine and stimulants in the diet from food, beverages, and dietary supplements, so that individuals do not unknowingly consume excess caffeine in their diet. 


\section{Conclusion}

EDs, shots, and PWSs are popular beverages in the society today. Most contain carbohydrate, caffeine, and other nutrients purported to improve exercise and/or cognitive performance. The preponderance of scientific evidence to date suggests that consumption of these products prior to exercise can improve anaerobic and endurance exercise capacity and/or cognitive performance without untoward side effects. ${ }^{2}$ However, the amount of caffeine and other stimulants contained in EDs, ESs, and PWSs needs to be considered as part of the total daily intake from food and beverages, so that individuals do not unknowingly consume excessive amounts of sugar and/or caffeine. Additionally, it is prudent for individuals with uncontrolled hypertension, arrhythmias, diabetes mellitus, peripheral artery disease, and/or cardiovascular disease to avoid use of EDs, ESs, and/or PWSs with known cardiostimulant effects. Additional research should evaluate the acute and chronic safety and efficacy of ingesting EDs, ESs, and PWSs on health and performance.

\section{Disclosure}

RBK received external funding from industry through the institutions he has been affiliated with to conduct exercise and nutrition research. RBK has served as a legal expert on exercise- and nutrition-related cases, and formerly served as a scientific advisor for Nutrabolt. The author reports no other conflicts of interest in this work.

\section{References}

1. Froiland K, Koszewski W, Hingst J, Kopecky L. Nutritional supplement use among college athletes and their sources of information. Int J Sport Nutr Exerc Metab. 2004;14(1):104-120.

2. Campbell B, Wilborn C, La Bounty P, et al. International Society of Sports Nutrition position stand: energy drinks. J Int Soc Sports Nutr. 2013;10(1): 1 .

3. Kreider RB, Wilborn CD, Taylor L, et al. ISSN exercise \& sport nutrition review: research \& recommendations. J Int Soc Sports Nutr. 2010;7:7.

4. Kreider RB, Hill D, Horton G, Downes M, Smith S, Anders B. Effects of carbohydrate supplementation during intense training on dietary patterns, psychological status, and performance. Int J Sport Nutr. 1995;5(2):125-135.

5. Aslankeser Z, Balci SS. Re-examination of the contribution of substrates to energy expenditure during high-intensity intermittent exercise in endurance athletes. Peer J. 2017;5:e3769.

6. American College of Sports Medicine; American Dietetic Association; Dietitians of Canada. Joint Position Statement: nutrition and athletic performance. American College of Sports Medicine, American Dietetic Association, and Dietitians of Canada. Med Sci Sports Exerc. 2000;32(12):2130-2145.

7. Goldstein E, Ziegenfuss T, Kalman D, et al. International society of sports nutrition position stand: caffeine and performance. J Int Soc Sports Nutr. 2010;7(1):5.

8. Ivy JL, Kammer L, Ding Z, et al. Improved cycling time-trial performance after ingestion of a caffeine energy drink. Int J Sport Nutr Exerc Metab. 2009;19(1):61-78.
9. Hespel P, Maughan RJ, Greenhaff PL. Dietary supplements for football. J Sports Sci. 2006;24(7):749-761.

10. Tinsley GM, Hamm MA, Hurtado AK, et al. Effects of two pre-workout supplements on concentric and eccentric force production during lower body resistance exercise in males and females: a counterbalanced, double-blind, placebo-controlled trial. J Int Soc Sports Nutr. 2017;14:46.

11. Jung YP, Earnest CP, Koozehchian M, et al. Effects of ingesting a preworkout dietary supplement with and without synephrine for 8 weeks on training adaptations in resistance-trained males. J Int Soc Sports Nutr. 2017;14:1

12. Goldstein E, Jacobs PL, Whitehurst M, Penhollow T, Antonio J. Caffeine enhances upper body strength in resistance-trained women. J Int Soc Sports Nutr. 2010;7:18.

13. Astorino TA, Roberson DW. Efficacy of acute caffeine ingestion for short-term high-intensity exercise performance: a systematic review. J Strength Cond Res. 2010;24(1):257-265.

14. Davis JK, Green JM. Caffeine and anaerobic performance: ergogenic value and mechanisms of action. Sports Med. 2009;39(10):813-832.

15. Rodriguez NR, Di Marco NM, Langley S. American College of Sports Medicine position stand. Nutrition and athletic performance. Med Sci Sports Exerc. 2009;41(3):709-731.

16. Kerksick C, Harvey T, Stout J, et al. International Society of Sports Nutrition position stand: nutrient timing. J Int Soc Sports Nutr. 2008;5:17.

17. Kerksick CM, Arent S, Schoenfeld BJ, et al. International society of sports nutrition position stand: nutrient timing. J Int Soc Sports Nutr. 2017;14:33.

18. Position of Dietitians of Canada, the American Dietetic Association, and the American College of Sports Medicine: Nutrition and Athletic Performance. Can J Diet Pract Res. 2000;61(4):176-192.

19. Position of the American Dietetic Association, Dietitians of Canada, and the American College of Sports Medicine: Nutrition and athletic performance. J Am Diet Assoc. 2000;100(12):1543-1556.

20. Alford C, Cox H, Wescott R. The effects of red bull energy drink on human performance and mood. Amino Acids. 2001;21(2):139-150.

21. Rahnama N, Gaeini AA, Kazemi F. The effectiveness of two energy drinks on selected indices of maximal cardiorespiratory fitness and blood lactate levels in male athletes. J Res Med Sci. 2010;15(3):127-132.

22. Forbes SC, Candow DG, Little JP, Magnus C, Chilibeck PD. Effect of Red Bull energy drink on repeated Wingate cycle performance and bench-press muscle endurance. Int J Sport Nutr Exerc Metab. 2007;17(5):433-444.

23. Del Coso J, Munoz-Fernandez VE, Munoz G, et al. Effects of a caffeinecontaining energy drink on simulated soccer performance. PLoS One. 2012;7(2):e31380.

24. Gonzalez AM, Walsh AL, Ratamess NA, Kang J, Hoffman JR. Effect of a pre-workout energy supplement on acute multi-joint resistance exercise. J Sports Sci Med. 2011;10(2):261-266.

25. Candow DG, Kleisinger AK, Grenier S, Dorsch KD. Effect of sugarfree Red Bull energy drink on high-intensity run time-to-exhaustion in young adults. $J$ Strength Cond Res. 2009;23(4):1271-1275.

26. Astorino TA, Rohmann RL, Firth K. Effect of caffeine ingestion on one-repetition maximum muscular strength. Eur J Appl Physiol. 2008;102(2):127-132.

27. Schubert MM, Astorino TA, Azevedo JL, Jr. The effects of caffeinated "energy shots" on time trial performance. Nutrients. 2013;5(6): 2062-2075.

28. Seifert JG, Connor DA. The influence of commercial energy shots on response time and power output in recreational cyclists. J Int Soc Sports Nutr. 2014;11(1):56.

29. Marczinski CA, Stamates AL, Ossege J, Maloney SF, Bardgett ME, Brown CJ. Subjective state, blood pressure, and behavioral control changes produced by an "Energy Shot". J Caffeine Res. 2014;4(2): $57-63$.

30. Monaghan TP, Jacobson BH, Sellers JH, Estrada CA. Effects of energy beverage consumption on pistol aiming steadiness in law enforcement officers. J Strength Cond Res. 2017;31(9):2557-2561. 
31. Walsh AL, Gonzalez AM, Ratamess NA, Kang J, Hoffman JR. Improved time to exhaustion following ingestion of the energy drink Amino Impact. J Int Soc Sports Nutr. 2010;7:14.

32. Hoffman JR, Ratamess NA, Ross R, Shanklin M, Kang J, Faigenbaum AD. Effect of a pre-exercise energy supplement on the acute hormonal response to resistance exercise. J Strength Cond Res. 2008;22(3): 874-882.

33. Smith AE, Fukuda DH, Kendall KL, Stout JR. The effects of a preworkout supplement containing caffeine, creatine, and amino acids during three weeks of high-intensity exercise on aerobic and anaerobic performance. J Int Soc Sports Nutr. 2010;7:10.

34. Jagim AR, Jones MT, Wright GA, St Antoine C, Kovacs A, Oliver JM. The acute effects of multi-ingredient pre-workout ingestion on strength performance, lower body power, and anaerobic capacity. J Int Soc Sports Nutr. 2016;13:11.

35. Martinez N, Campbell B, Franek M, Buchanan L, Colquhoun R. The effect of acute pre-workout supplementation on power and strength performance. J Int Soc Sports Nutr. 2016;13:29.

36. Jung YP, Earnest CP, Koozehchian M, et al. Effects of acute ingestion of a pre-workout dietary supplement with and without p-synephrine on resting energy expenditure, cognitive function and exercise performance. J Int Soc Sports Nutr. 2017;14:3.

37. Collins PB, Earnest CP, Dalton RL, et al. Short-term effects of a readyto-drink pre-workout beverage on exercise performance and recovery Nutrients. 2017;9(8).

38. Cameron M, Camic CL, Doberstein S, Erickson JL, Jagim AR. The acute effects of a multi-ingredient pre-workout supplement on resting energy expenditure and exercise performance in recreationally active females. J Int Soc Sports Nutr. 2018;15:1.

39. Seidl R, Peyrl A, Nicham R, Hauser E. A taurine and caffeine-containing drink stimulates cognitive performance and well-being. Amino Acids. 2000;19(3-4):635-642.

40. Howard MA, Marczinski CA. Acute effects of a glucose energy drink on behavioral control. Exp Clin Psychopharmacol. 2010;18(6): 553-561.

41. Mets MA, Ketzer S, Blom C, et al. Positive effects of Red Bull(R) Energy Drink on driving performance during prolonged driving. Psychopharmacology (Berl). 2011;214(3):737-745.

42. Wesnes KA, Brooker H, Watson AW, Bal W, Okello E. Effects of the Red Bull energy drink on cognitive function and mood in healthy young volunteers. J Psychopharmacol. 2017;31(2):211-221.

43. Rao A, Hu H, Nobre AC. The effects of combined caffeine and glucose drinks on attention in the human brain. Nutr Neurosci. 2005;8(3):141-153.

44. Scholey AB, Kennedy DO. Cognitive and physiological effects of an "energy drink": an evaluation of the whole drink and of glucose, caffeine and herbal flavouring fractions. Psychopharmacology (Berl). 2004;176(3-4):320-330.

45. Smit HJ, Cotton JR, Hughes SC, Rogers PJ. Mood and cognitive performance effects of "energy" drink constituents: caffeine, glucose and carbonation. Nutr Neurosci. 2004;7(3):127-139.

46. Hoffman JR, Kang J, Ratamess NA, Hoffman MW, Tranchina CP, Faigenbaum AD. Examination of a pre-exercise, high energy supplement on exercise performance. J Int Soc Sports Nutr. 2009;6:2.

47. Ormsbee MJ, Mandler WK, Thomas DD, et al. The effects of six weeks of supplementation with multi-ingredient performance supplements and resistance training on anabolic hormones, body composition, strength, and power in resistance-trained men. J Int Soc Sports Nutr. 2012;9(1):49.

48. Kedia AW, Hofheins JE, Habowski SM, Ferrando AA, Gothard MD, Lopez HL. Effects of a pre-workout supplement on lean mass, muscular performance, subjective workout experience and biomarkers of safety. Int J Med Sci. 2014;11(2):116-126.

49. Arent SM, Walker AJ, Pellegrino JK, et al. The combined effects of exercise, diet, and a multi-ingredient dietary supplement on body composition and adipokine changes in overweight adults. J Am Coll Nutr. 2018;37(2):111-120.
50. Lockwood CM, Moon JR, Smith AE, et al. Low-calorie energy drink improves physiological response to exercise in previously sedentary men: a placebo-controlled efficacy and safety study. J Strength Cond Res. 2010;24(8):2227-2238.

51. Ormsbee MJ, Thomas DD, Mandler WK, et al. The effects of pre- and post-exercise consumption of multi-ingredient performance supplements on cardiovascular health and body fat in trained men after six weeks of resistance training: a stratified, randomized, double-blind study. Nutr Metab (Lond). 2013;10(1):39.

52. Outlaw JJ, Wilborn CD, Smith-Ryan AE, et al. Acute effects of a commercially-available pre-workout supplement on markers of training: a double-blind study. J Int Soc Sports Nutr. 2014;11:40.

53. Vogel RM, Joy JM, Falcone PH, Mosman MM, Kim MP, Moon JR. Consuming a multi-ingredient thermogenic supplement for 28 days is apparently safe in healthy adults. Food Nutr Res. 2015;59:27999.

54. Kreipke VC, Allman BR, Kinsey AW, Moffatt RJ, Hickner RC, Ormsbee MJ. Impact of four weeks of a multi-ingredient performance supplement on muscular strength, body composition, and anabolic hormones in resistance-trained young men. J Strength Cond Res. 2015;29(12):3453-3465.

55. Kohne JL, Ormsbee MJ, McKune AJ. The effects of a multi-ingredient supplement on markers of muscle damage and inflammation following downhill running in females. J Int Soc Sports Nutr. 2016;13:44.

56. Naclerio F, Larumbe-Zabala E. Effects of whey protein alone or as part of a multi-ingredient formulation on strength, fat-free mass, or lean body mass in resistance-trained individuals: a meta-analysis. Sports Med. 2016;46(1):125-137.

57. Garcia A, Romero C, Arroyave C, Giraldo F, Sanchez L, Sanchez J. Acute effects of energy drinks in medical students. Eur J Nutr. 2017;56(6):2081-2091.

58. Peveler WW, Sanders GJ, Marczinski CA, Holmer B. Effects of energy drinks on economy and cardiovascular measures. J Strength Cond Res. 2017;31(4):882-887.

59. Ferreira SE, de Mello MT, Rossi MV, Souza-Formigoni ML. Does an energy drink modify the effects of alcohol in a maximal effort test? Alcohol Clin Exp Res. 2004;28(9):1408-1412.

60. Molnar J, Somberg JC. Evaluation of the effects of different energy drinks and coffee on endothelial function. Am J Cardiol. 2015;116(9):1457-1460.

61. Reissig CJ, Strain EC, Griffiths RR. Caffeinated energy drinks--a growing problem. Drug Alcohol Depend. 2009;99(1-3):1-10.

62. Manchester J, Eshel I, Marion DW. The benefits and risks of energy drinks in young adults and military service members. Mil Med. 2017;182(7):e1726-e1733.

63. Nordt SP, Claudius I, Rangan C, et al. Reasons for energy drink use and reported adverse effects among adolescent emergency department patients. Pediatr Emerg Care. 2017;33(12):770-773.

64. Rahamathulla MP. Prevalence, side effects and awareness about energy drinks among the female university students in Saudi Arabia. PakJ Med Sci. 2017;33(2):347-352.

65. Riesselmann B, Rosenbaum F, Schneider V. Alcool et boisson énergétique la consommation combinée des deux boissons modifie l'automobile conduite de fitness? [Alcohol and energy drink--can combined consumption of both beverages modify automobile driving fitness?]. Blutalkohol. 1996;33(4):201-208. German

66. Oteri A, Salvo F, Caputi AP, Calapai G. Intake of energy drinks in association with alcoholic beverages in a cohort of students of the School of Medicine of the University of Messina. Alcohol Clin Exp Res. 2007;31(10):1677-1680.

67. Curry K, Stasio MJ. The effects of energy drinks alone and with alcohol on neuropsychological functioning. Hum Psychopharmacol. 2009;24(6):473-481.

68. Marczinski CA, Fillmore MT, Maloney SF, Stamates AL. Faster selfpaced rate of drinking for alcohol mixed with energy drinks versus alcohol alone. Psychol Addict Behav. 2017;31(2):154-161.

69. Sweeney MM, Meredith SE, Evatt DP, Griffiths RR. Effects of caffeine on alcohol reinforcement: beverage choice, self-administration, and subjective ratings. Psychopharmacology (Berl). 2017;234(5):877-888. 
70. O'Brien MC, McCoy TP, Rhodes SD, Wagoner A, Wolfson M. Caffeinated cocktails: energy drink consumption, high-risk drinking, and alcohol-related consequences among college students. Acad Emerg Med. 2008;15(5):453-460.

71. Thombs DL, O’Mara RJ, Tsukamoto M, et al. Event-level analyses of energy drink consumption and alcohol intoxication in bar patrons. Addict Behav. 2010;35(4):325-330.

72. Malinauskas BM, Aeby VG, Overton RF, Carpenter-Aeby T, BarberHeidal K. A survey of energy drink consumption patterns among college students. Nutr J. 2007;6:35.

73. Jackson DB, Leal WE. Energy drink consumption and the perceived risk and disapproval of drugs: monitoring the Future, 2010-2016. Drug Alcohol Depend. 2018;188:24-31.

74. Dawodu A, Cleaver K. Behavioural correlates of energy drink consumption among adolescents: a review of the literature. J Child Health Care. 2017;21(4):446-462.

75. De Sanctis V, Soliman N, Soliman AT, et al. Caffeinated energy drink consumption among adolescents and potential health consequences associated with their use: a significant public health hazard. Acta Biomed. 2017;88(2):222-231.

76. Emond JA, Gilbert-Diamond D, Tanski SE, Sargent JD. Energy drink consumption and the risk of alcohol use disorder among a national sample of adolescents and young adults. J Pediatr. 2014;165(6): 1194-1200.

77. Droste N, Tonner L, Zinkiewicz L, Pennay A, Lubman DI, Miller P. Combined alcohol and energy drink use: motivations as predictors of consumption patterns, risk of alcohol dependence, and experience of injury and aggression. Alcohol Clin Exp Res. 2014;38(7): 2087-2095.

78. Peacock A, Bruno R, Martin FH, Carr A. The impact of alcohol and energy drink consumption on intoxication and risk-taking behavior. Alcohol Clin Exp Res. 2013;37(7):1234-1242.

79. Snipes DJ, Benotsch EG. High-risk cocktails and high-risk sex: examining the relation between alcohol mixed with energy drink consumption, sexual behavior, and drug use in college students. Addict Behav. 2013;38(1):1418-1423.
80. Velazquez CE, Poulos NS, Latimer LA, Pasch KE. Associations between energy drink consumption and alcohol use behaviors among college students. Drug Alcohol Depend. 2012;123(1-3):167-172.

81. Arria AM, Caldeira KM, Kasperski SJ, Vincent KB, Griffiths RR, O'Grady KE. Energy drink consumption and increased risk for alcohol dependence. Alcohol Clin Exp Res. 2011;35(2):365-375.

82. Howland J, Rohsenow DJ. Risks of energy drinks mixed with alcohol. JAMA. 2013;309(3):245-246.

83. Sepkowitz KA. Energy drinks and caffeine-related adverse effects. JAMA. 2013;309(3):243-244.

84. Torpy JM, Livingston EH. JAMA patient page. Energy drinks. JAMA. 2013;309(3):297.

85. Szpak A, Allen D. A case of acute suicidality following excessive caffeine intake. J Psychopharmacol. 2012;26(11):1502-1510.

86. Wolk BJ, Ganetsky M, Babu KM. Toxicity of energy drinks. Curr Opin Pediatr. 2012;24(2):243-251.

87. Fogger S, McGuinness TM. Update on energy drinks and youth. J Psychosoc Nurs Ment Health Serv. 2011;49(12):17-19.

88. Berger AJ, Alford K. Cardiac arrest in a young man following excess consumption of caffeinated "energy drinks". Med JAust. 2009;190(1):41-43.

89. The facts about caffeine in dietary supplements 2016. Available from: https:/www.crnusa.org/system/files/2016-11/CRN_Factsheet_Caffeine_0416_0.pdf. Accessed February 26, 2018.

90. Clauson KA, Shields KM, McQueen CE, Persad N. Safety issues associated with commercially available energy drinks. J Am Pharm Assoc (2003). 2008;48(3):e55-e63; quiz e64-7.

91. Petit A, Levy F, Lejoyeux M, Reynaud M, Karila L. Boissons énergisantes: un risque inconnu [Energy drinks: an unknown risk]. Rev Prat. 2012;62(5):673-678. French

92. Heckman MA, Weil J, Gonzalez de Mejia E. Caffeine (1, 3, 7-trimethylxanthine) in foods: a comprehensive review on consumption, functionality, safety, and regulatory matters. J Food Sci. 2010;75(3):R77-R87.

93. Nawrot P, Jordan S, Eastwood J, Rotstein J, Hugenholtz A, Feeley M. Effects of caffeine on human health. Food Addit Contam. 2003;20(1):1-30.

94. Higdon JV, Frei B. Coffee and health: a review of recent human research. Crit Rev Food Sci Nutr. 2006;46(2):101-123.
Nutrition and Dietary Supplements

\section{Publish your work in this journal}

Nutrition and Dietary Supplements is an international, peer-reviewed, open access journal focusing on research into nutritional requirements in health and disease, impact on metabolism and the identification and optimal use of dietary strategies and supplements necessary for normal growth and development. The journal welcomes submitted papers covering original research, basic science,
Dovepress

clinical \& epidemiological studies, reviews and evaluations, guidelines, expert opinion and commentary, case reports and extended reports. The manuscript management system is completely online and includes a very quick and fair peer-review system, which is all easy to use. Visit http://www.dovepress.com/ testimonials.php to read real quotes from published authors. 